\title{
Efficacy of amniotic membrane-assisted bleb revision for elevated intraocular pressure after filtering surgery
}

This article was published in the following Dove Press journal:

Clinical Ophthalmology

22 July 2010

Number of times this article has been viewed

\author{
Yoshiaki Kiuchi' \\ Masahide Yanagi' \\ Takao Nakamura ${ }^{2}$ \\ 'Department of Ophthalmology \\ and Visual Sciences, Hiroshima \\ University, Hiroshima, ${ }^{2}$ Department \\ of Ophthalmology, Otemae Hospital, \\ Osaka, Japan
}

Purpose: To compare the effectiveness of standard revision surgery using mitomycin $\mathrm{C}$ (MMC) with revision using amniotic membrane transplantation and $\mathrm{MMC}$ for elevated intraocular pressure (IOP) after trabeculectomy.

Patients and methods: A retrospective, nonrandomized comparative study of 36 eyes of 36 patients with a failed trabeculectomy. Patients were divided into two groups, ie, a nonamniontransplanted group and an amnion-transplanted group. The amniotic membrane was placed on the scleral flap under the conjunctiva in the amnion-transplanted group. Both groups recovered filtration of aqueous humor from the surgical site with the adjunctive use of MMC. The changes in IOP and cumulative survival rate were compared for the two groups. Success was defined as a $30 \%$ reduction in IOP from the preoperative IOP and maintenance below $21 \mathrm{mmHg}$ with or without the use of antiglaucomatous agents.

Results: The mean preoperative IOP was not significantly different in the two groups. The mean postoperative IOP in the nonamnion group, $12.1 \pm 5.5 \mathrm{mmHg}$, was significantly lower than the IOP in the amnion group, $16.0 \pm 3.7 \mathrm{mmHg}$. Survival curves in the two groups did not reach significantly different levels.

Conclusions: Conventional surgical bleb revision with MMC can significantly reduce the elevated IOP associated with a failed filtration bleb. The use of an amniotic membrane transplant did not improve the surgical outcome in our cases.

Keywords: filtration bleb revision, amniotic membrane, mitomycin C, filtering surgery

\section{Introduction}

Trabeculectomy has been the surgery of choice in eyes with glaucoma since it was first described by Cairns in $1968 .{ }^{1}$ Antifibrotic drugs, such as 5-fluorouracil and mitomycin $\mathrm{C}(\mathrm{MMC})$, have been commonly used adjunctively to prevent scar formation, and they have increased the success rate of trabeculectomy. However, there is still a low but unacceptable rate of failure of trabeculectomy because of progressive scarring of the subconjunctival tissues. Patients with secondary glaucoma, aphakia, and prior surgery to the conjunctiva are reported to have poorer success rates following trabeculectomy. ${ }^{2}$

When filtration surgery fails to reduce the intraocular pressure (IOP), a revision of the bleb is one of the options. Several investigators have advocated bleb revision with adjunctive 5-fluorouracil or MMC, ${ }^{3}$ while others have advocated the use of an amniotic transplant. ${ }^{4-7}$ The amniotic membrane is the innermost layer of the three-layered fetal membrane, and has anti-inflammatory, antifibrotic, and antiangiogenic properties. ${ }^{8,9}$ Amniotic membranes have been transplanted to reconstruct the ocular surface after
Hiroshima University, Department of Ophthalmology and Visual Sciences I-2-3 Kasumi, Minami-ku, Hiroshima, 734-855I, Japan

Tel +81822575247

Fax +8I 822575249

Email ykiuchi@hiroshima-u.ac.jp 
pterygium excision ${ }^{10}$ and in nonhealing corneal epithelial defects. ${ }^{11}$ Nagai-Kusuhara et al reported that the use of an amniotic membrane for reconstructing a filtration bleb is useful for late-onset bleb leaks. ${ }^{12}$ Because of its ability to suppress wound healing, amniotic membrane transplantation has been used in glaucoma-filtering surgery to prevent subconjunctival fibrosis. ${ }^{4-7}$

The purpose of this study was to assess the effectiveness of conventional surgical revision using adjunctive MMC with that of bleb revision using adjunctive MMC and transplantation of an amniotic membrane in lowering IOP.

\section{Material and methods}

The medical charts of 36 eyes of 36 patients who had undergone trabeculectomy and bleb revision by a single surgeon (YK) at the Otemae Hospital from February 2003 to July 2006 were reviewed. This study was approved by the Otemae Hospital Institutional Review Board, and the procedures used conformed to the tenets of the Declaration of Helsinki. Informed consent for the surgery had been obtained in all cases.

Two groups were compared; there were 24 eyes in the nonamnion-transplanted groups and 12 eyes in the amniontransplanted group. The patients in the nonamnion group had conventional bleb revision with adjunctive MMC between February 2003 and July 2005. The remaining 12 patients had bleb revision with amniotic membrane transplantation and MMC between August 2005 and July 2006.

The surgical procedures were slightly modified from those reported by Drolsum et al. ${ }^{6}$ For the surgery, the conjunctiva was anesthetized with a $1 \mathrm{~mL}$ injection of $2 \%$ xylocaine, and a conjunctival incision was made approximately $9 \mathrm{~mm}$ from the limbus or at the limbus. All of the cases in the nonamnion group had limbus-based surgery. For this, the conjunctiva was separated from the sclera, and the scar tissue was dissected from the scleral surface both anteriorly and posteriorly. After applying $0.4 \mathrm{mg} / \mathrm{mL}$ MMC to the sclera for five minutes, the surgical area was irrigated with $100 \mathrm{~mL}$ of balanced salt solution. The wall of the bleb or fibrotic membrane on the scleral flap was reopened as confirmed by the leakage of aqueous humor. The conjunctiva was closed with a 10-0 nylon running suture.

The amniotic membrane was obtained under sterile conditions after a cesarean delivery and cryopreserved at $-80^{\circ} \mathrm{C}$ in dimethyl sulfoxide until immediately before use. In the amnion group, a piece of amniotic membrane measuring approximately $7 \times 10 \mathrm{~mm}$ was placed with the epithelial side over the scleral flap. Six of 12 cases $(50 \%)$ in the amnion group had limbus-based surgery, and the remaining six cases had fornix-based surgery. The amniotic membrane was sutured to the sclera at the corneoscleral limbus using 8-0 virgin silk. The fornix side of the amniotic membrane was inserted beneath the healthy conjunctiva posterior to the conjunctival incision line or scar line. Then two to three sutures were placed $5 \mathrm{~mm}$ from the limbus to fix the amniotic membrane to the sclera. The fornix end of the membrane was not sutured. Then the limbus-based conjunctival flap was closed, as was done in the nonamnionic group. The fornixbased flap was closed by interrupted sutures at the limbus.

Postoperatively, all patients received similar topical medical regimen; $0.1 \%$ topical betamethasone and $0.5 \%$ levofloxacin for six weeks to three months which was reduced within three months, depending on the degree of inflammation. Patients were examined monthly for the first 3 months, and every 2-3 months thereafter.

The success of these surgical procedures was compared using Kaplan-Meier lifetable analysis. Success was defined as a $30 \%$ reduction of the IOP from the preoperative IOP and maintenance below $21 \mathrm{mmHg}$ with or without the use of antiglaucoma agents. When additional surgery was performed, the IOP control was judged as a failure regardless of IOP at the time of the decision.

Survival curves were constructed for the two groups. The significance of the differences in success was determined using the log rank test. When the IOP was higher than the targeted pressure in two consecutive examinations, the bleb was considered to have failed. When additional glaucoma surgery was performed, the IOP control was judged as a failure regardless of the IOP level at the time of the decision.

The significance of the differences in the demographic characteristics of the subjects and the incidence of surgical complications were determined using Mann-Whitney U tests and Fisher's Exact probability tests. The IOP changes were evaluated using Mann-Whitney tests and Wilcoxon signedrank tests. A $P$ value of $<0.05$ was considered statistically significant.

\section{Results}

The demographic data of the patients are summarized in Tables 1 and 2. There were no significant differences in age, duration of follow-up, preoperative IOP, number of prior surgeries, number of prescribed antiglaucoma medications, and type of glaucoma between the nonamnion amnion groups.

The pretrabeculectomy (former trabeculectomy before revision) IOPs were $21.2 \pm 4.0 \mathrm{mmHg}$ in the nonamnion group and $21.8 \pm 3.8 \mathrm{mmHg}$ in the amnion group. 
Table I Patient demographics

\begin{tabular}{|c|c|c|c|}
\hline & \multicolumn{3}{|c|}{ Amniotic membrane } \\
\hline & \multirow{2}{*}{$\frac{-}{(n=24)}$} & \multicolumn{2}{|l|}{+} \\
\hline & & $(n=12)$ & $P$ value \\
\hline \multicolumn{4}{|l|}{ Age (years) } \\
\hline Mean \pm SD & $61.7 \pm 13.1$ & $61.4 \pm 16.6$ & $0.675^{*}$ \\
\hline Range & $36-84$ & $38-83$ & \\
\hline \multicolumn{4}{|c|}{ Follow-up period (months) } \\
\hline Mean \pm SD & $9.6 \pm 4.5$ & $9.6 \pm 4.9$ & $0.93 I^{*}$ \\
\hline Range & $6-20$ & $6-16$ & \\
\hline \multicolumn{4}{|c|}{ Preoperative IOP (mmHg) } \\
\hline Mean \pm SD & $21.4 \pm 6.5$ & $21.8 \pm 4.6$ & $0.469 *$ \\
\hline Range & $15-48$ & $16-30$ & \\
\hline \multicolumn{4}{|l|}{ Prior surgeries } \\
\hline Cataract & 15 & 9 & $0.708^{\dagger}$ \\
\hline Vitrectomy & 4 & 6 & $0.053^{\dagger}$ \\
\hline Filtering & 15 & 6 & $0.499^{\dagger}$ \\
\hline Surgery & 9 & 6 & \\
\hline Number of eye drops & $1.4 \pm 0.9$ & $1.5 \pm 1.0$ & $0.918^{*}$ \\
\hline
\end{tabular}

*Mann-Whitney's $U$ test; 'Fisher's exact probability test.

Abbreviations: SD, standard deviation; IOP, intraocular pressure.

The mean prebleb revision IOP was $21.4 \pm 6.5 \mathrm{mmHg}$ in the nonamnion group and $21.8 \pm 4.6 \mathrm{mmHg}$ in the amnion group. The postoperative IOP at the last visit in the nonamnion group was $12.1 \pm 5.5 \mathrm{mmHg}$ and that in the amnion group was $16.0 \pm 3.7 \mathrm{mmHg}$. In each group, the IOP was reduced significantly, although the IOP in the nonamniotic group was significantly lower than that in the amniotic group $(P=0.025)$. The number of postoperative antiglaucoma eye drops was $0.24 \pm 0.60$ in the nonamnion group and $0.58 \pm 0.79$ in the amnion group $(P=0.105)$.

In the amnion group, Kaplan-Meier lifetable analysis showed that the success rate was $58.3 \%$ after six months and $21.9 \%$ after one year. The success rate in the nonamnion group was $74.8 \%$ from six months to one year after surgery. This difference in the surgical outcome was not significant $(P=0.109$, see Figure 1).

At the final visit, five eyes had survived in the amnion group according to our criterion for success. Two had a fornixbased conjunctival flap, and three had a limbus-based flap.

Table 2 Type of glaucoma

\begin{tabular}{llll}
\hline & \multicolumn{3}{l}{ Amniotic membrane } \\
\cline { 2 - 4 } & - & + & \\
\cline { 2 - 4 } & $(\mathbf{n}=\mathbf{2 4})$ & $\mathbf{( n = 1 2 )}$ & $\mathbf{P}$ value \\
\hline Primary open angle glaucoma & $\mathrm{II}$ & 7 & 0.725 \\
Exfoliation syndrome & 2 & 0 & 0.543 \\
Glaucoma secondary to uveitis & 4 & $\mathrm{I}$ & 0.635 \\
Neovascular glaucoma & 5 & 4 & 0.416 \\
Others & 2 & 0 & 0.543 \\
\hline
\end{tabular}

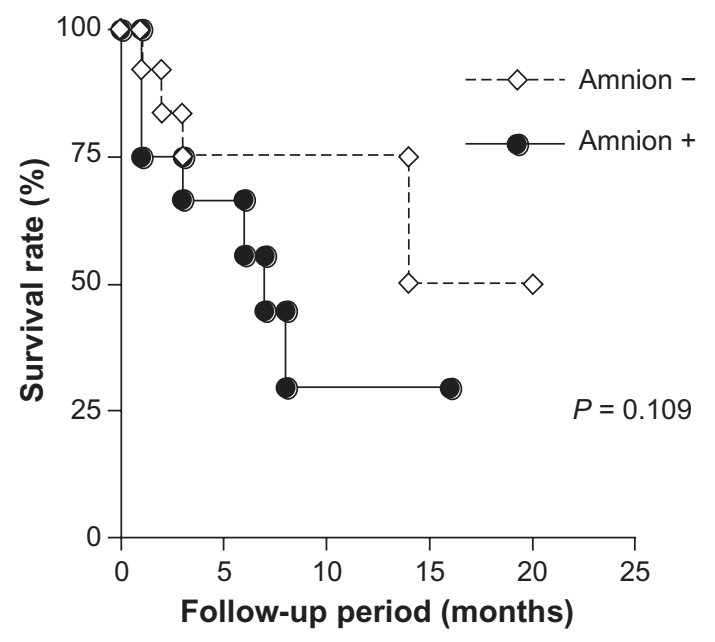

Figure I Kaplan-Meier survival curves of the amnion and nonamnion transplant groups. A plot of the cumulative probabilities against time that the intraocular pressure was $30 \%$ lower than at baseline.

The postoperative complications are listed in Table 3. Two cases of hyphema were seen in the nonamnion group and one in the amnion group. Leakage at the wound edge developed in one case in the nonamnion group and three cases in the amnion group. Conjunctival sutures were used to repair the wound leakage. Hyphema, shallow anterior chamber, and choroidal detachment resolved without any intervention.

Late complications of trabeculectomy such as hypotonic maculopathy, late bleb leak, bleb-associated infection, and corneal decompensation were not found in any of our patients.

Although appearance of the bleb is an important factor that predicts IOP results and bleb-related complications, we did not evaluate bleb appearance in this study. All of the subjects had had ocular surgery several times and had cicatricial conjunctiva.

\section{Discussion}

Kaplan-Meier lifetable analyses showed that the success rate in the nonamniotic group was $74.8 \%$ from six months to one year after the surgery. The mean IOP was reduced significantly from $21.4 \pm 6.5 \mathrm{mmHg}$ to $12.1 \pm 5.5 \mathrm{mmHg}$ in the nonamnion group $(P<0.001)$. These findings are in good agreement with those of Hara and Shirato ${ }^{13}$ who reported that an IOP under $21 \mathrm{mmHg}$ was achieved in 53.4\% without medication and in $60.2 \%$ with and without medication at 60 months following conventional bleb revision surgery. Anand and Arora ${ }^{14}$ reported that the probability of maintaining an IOP between 5 and $18 \mathrm{mmHg}$ or a $20 \%$ decrease from the preoperative IOP was $64 \%$ at three years after 
Table 3 Postoperative complications

\begin{tabular}{llll}
\hline & \multicolumn{3}{l}{ Amniotic membrane } \\
\cline { 2 - 4 } & - & + & \\
\cline { 2 - 4 } & $(\mathbf{n}=\mathbf{2 4})$ & $(\mathbf{n}=\mathbf{I 2})$ & $\boldsymbol{P}$ value \\
\hline Shallow anterior chamber & $\mathrm{I}$ & 0 & $>0.999$ \\
Choroidal detachment & $\mathrm{I}$ & 0 & $>0.999$ \\
Hyphema & 2 & $\mathrm{I}$ & $>0.999$ \\
Wound leakage & $\mathrm{I}$ & 3 & 0.098 \\
\hline
\end{tabular}

conventional revision surgery. Earlier studies reported that the success rate of bleb revision was around $60 \%$ although there were some differences in the criteria for success. Thus, our results in the nonamnion group are in good agreement with these earlier findings.

While bleb revision with adjunctive MMC is an effective treatment in cases of bleb failure, glaucoma surgeons have been recently examining the effectiveness of amnion membrane transplantation. The amniotic membrane is made of strong and stable collagen, and has good anti-inflammatory, antifibrotic, and antiangiogenic properties. In glaucoma filtration surgery, the healing response is characterized by fibroblast outgrowth, and the fibrosis has been reported to be delayed more by an amniotic membrane than with conventional conjunctival closure. ${ }^{5}$

For amniotic membrane transplantation, Fujishima et $\mathrm{al}^{4}$ transplanted the amniotic membrane under a scleral flap and sutured it to the sclera. For the 14 eyes of the 13 patients with treatment-resistant glaucoma, the IOP was reduced to $<20 \mathrm{mmHg}$ after surgery in 13 eyes. Drolsum et al ${ }^{6}$ used a large amniotic membrane, and sutured it to the scleral surface, and one end was positioned under the scleral flap and the other end was secured to subconjunctival tissue. The mean preoperative IOP was $32.2 \mathrm{mmHg}$, and the mean postoperative IOP was $16.4 \mathrm{mmHg}$. Although there were differences in the methods and definition of success, they reported that amniotic membrane transplantation was good for the revision of failed glaucoma filtering blebs. ${ }^{46}$

These reports encouraged us to try to use the amniotic membrane for bleb revision. One year after starting the use of amniotic membranes, we evaluated the efficacy of amniotic membrane transplantation to repair failed filtration blebs, and compared that with conventional bleb revision. KaplanMeier lifetable analyses showed that bleb revision with amniotic membrane transplantation was not better than conventional bleb revision with MMC in our cases. In fact, the postoperative IOP was significantly higher in the amniontransplanted group than in the nonamnion-transplanted group.
These results suggest that a subconjunctival placement of amniotic membrane does not improve the filtration in highrisk eyes. These poorer results using amniotic membranes for bleb revision discouraged us from recruiting new patients. So the number of the amnion group is smaller than the nonamnion group.

In the amnion group, six cases (50\%) were fornix-based, and all of the cases in the nonamnion group were limbusbased because a fornix-based conjunctival flap allowed us to fix the amniotic membrane at the edge easier than a limbusbased flap. Earlier studies ${ }^{15,16}$ reported that a fornix-based conjunctival flap and a limbus-based flap did not significantly alter the IOP-lowering effect of trabeculectomy. In our small amnion group, the success rates in the limbus-based group and fornix-based group were not significantly different. The IOP control results seemed to be unrelated to the surgical technique of handling the conjunctiva.

There are others who are more uncertain about the usefulness of amniotic membranes. Budenz et $\mathrm{al}^{17}$ stated that amniotic membrane transplantation did not offer an effective alternative to conjunctival advancement for repair of a leaking filtering bleb. The postoperative IOP in their amniotic membrane transplantation group was relatively higher than in the conjunctival advancement group, although the difference was not statistically significant. Demir et a ${ }^{18}$ concluded that amniotic membrane transplantation can depress wound healing in a rabbit model of glaucoma. However, the amniotic membrane was less effective than MMC.

Li et $a l^{19}$ described the usefulness of amniotic membrane transplantation for the repair of conjunctival buttonholes during trabeculectomy with MMC. They also discussed better ways to use amniotic membrane use during glaucoma surgery. They concluded that amniotic membrane transplantation was useful when used as a platform for re-epithelialization as opposed to tissue replacement for conjunctiva after bleb excision. They reported on the importance of the way the amniotic membrane was handled to obtain good surgical results. Recently, Sheha et $\mathrm{al}^{7}$ reported that amniotic transplantation in trabeculectomy with MMC for refractory glaucoma had achieved better IOP reduction than trabeculectomy with MMC alone. Although we sutured the amniotic membrane over the scleral flap, they placed a single layer of amniotic membrane under and around the scleral flap. All of these findings indicate that improvements in the surgical procedures for handling and placing the amniotic membrane are needed. For example, if the amniotic membrane is placed beneath the scleral flap, our outcome might have been improved. 
Amniotic membranes have antifibrotic effects. However, the antifibrotic effects are not as potent as that of MMC..$^{18}$ The ability of amniotic membrane transplantation to suppress the fibroblast proliferation of the conjunctiva in eyes with refractory glaucoma may not be strong enough to maintain a functional bleb. This can be another reason for the mixed results of amniotic membrane transplantation in glaucoma-filtering surgery. To use the amniotic membrane for bleb revision before the bleb becomes severely scarred may be one of the methods that might improve the surgical results.

There were no severe complications such as hypotonic maculopathy, late bleb leaks, and bleb-associated infection in our cases. Other reports of amniotic membrane transplantation have also reported no damaging complications. ${ }^{9-11}$

\section{Conclusion}

The revision of a failed filtering bleb with adjunctive MMC is an effective way of lowering IOP. The use of amniotic membrane transplantation did not enhance the surgical outcome in our cases. Establishing better ways to handle amniotic membrane may also be a key factor in improving surgical results.

\section{Acknowledgment}

We thank Dr Duco Hamasaki for editing this manuscript.

\section{Disclosure}

The authors have no financial or proprietary interest in any material or method mentioned in this study.

\section{References}

1. Cairns JE. Trabeculectomy. Preliminary report of a new method. Am J Ophthalmol. 1968;66:673-679.

2. Sturmer J, Broadway DC, Hitchings RA. Young patient trabeculectomy. Assessment of risk factors for failure. Ophthalmology. 1993; 100:928-939.
3. Anand N, Arora S. Surgical revision of failed filtration surgery with mitomycin C augmentation. J Glaucoma. 2007;16:456-461.

4. Fujishima H, Shimazaki J, Shinozaki N, et al. Trabeculectomy with the use of amniotic membrane for uncontrollable glaucoma. Ophthalmic Surg Lasers. 1998;29:428-431.

5. Barton K, Budenz DL, Khaw PT, et al. Glaucoma filtration surgery using amniotic membrane transplantation. Invest Ophthalmol Vis Sci. 2001;42:1762-1768.

6. Drolsum L, Willoch C, Nicolaissen B. Use of amniotic membrane as an adjuvant in refractory glaucoma. Acta Ophthalmol Scand. 2006;84: 786-789.

7. Sheha H, Kheirkhah A, Taha H. Amniotic membrane transplantation in trabeculectomy with mitomycin C for refractory glaucoma. J Glaucoma. 2008; 17:303-307.

8. Tseng SC, Li DQ, Ma X. Suppression of transforming growth factor-beta isoforms, TGF-beta receptor type II, and myofibroblast differentiation in cultured human corneal and limbal fibroblasts by amniotic membrane matrix. J Cell Physiol. 1999;179:325-335.

9. Dua HS, Gomes JA, King AJ, et al. The amniotic membrane in ophthalmology. Surv Ophthalmol. 2004;49:51-77.

10. Prabhasawat P, Barton K, Burkett G, et al. Comparison of conjunctival autografts and amniotic membrane grafts for pterygium excision. Ophthalmology. 1997;104:974-985.

11. Chen HJ, Pires RT, Tseng SC. Amniotic membrane transplantation for severe neurotrophic corneal ulcers. Br J Ophthalmol. 2000;84: 826-833.

12. Nagai-Kusuhara A, Nakamura M, Fujioka M, et al. Long-term results of amniotic membrane transplantation-assisted bleb revision for leaking blebs. Graefe Arch Clin Exp Ophthalmol. 2008;246:567-571.

13. Hara T, Shirato S. Surgical revision of failed filtering bleb with mitomycin C. Nippon Ganka Gakkai Zasshi. 1997;101:516-519.

14. Anand N, Arora S. Surgical revision of failed filtration surgery with mitomycin C augmentation. J Glaucoma. 2007;16:456-461.

15. Grehn F, Mauthe S, Pfeiffer N. Limbus-based versus fornix-based conjunctival flap in filtering surgery. A randomized prospective study. Int Ophthalmol. 1989;13:139-143.

16. el Sayyad F, el-Rashood A, Helal M, et al. Fornix-based versus limbal-based conjunctival flaps in initial trabeculectomy with postoperative 5-fluorouracil: Four-year follow-up findings. J Glaucoma. 1999;8:124-128.

17. Budenz DL, Barton K, Tseng SC. Amniotic membrane transplantation for repair of leaking glaucoma filtering blebs. Am J Ophthalmol. 2000;130:580-588.

18. Demir T, Turgut B, Akyol N, et al. Effects of amniotic membrane transplantation and mitomycin $\mathrm{C}$ on wound healing in experimental glaucoma surgery. Ophthalmologica. 2002;216:438-442.

19. Li G, O’Hearn T, Yiu S, et al. Amniotic membrane transplantation for intraoperative conjunctival repair during trabeculectomy with mitomycin C. J Glaucoma. 2007;16:521-526.
Clinical Ophthalmology

\section{Publish your work in this journal}

Clinical Ophthalmology is an international, peer-reviewed journal covering all subspecialties within ophthalmology. Key topics include: Optometry; Visual science; Pharmacology and drug therapy in eye diseases; Basic Sciences; Primary and Secondary eye care; Patient Safety and Quality of Care Improvements. This journal is indexed on

Submit your manuscript here: http://www.dovepress.com/clinical-ophthalmology-journal

\section{Dovepress}

PubMed Central and CAS, and is the official journal of The Society of Clinical Ophthalmology (SCO). The manuscript management system is completely online and includes a very quick and fair peer-review system, which is all easy to use. Visit http://www.dovepress.com/ testimonials.php to read real quotes from published authors. 